\title{
Block Chain in FaKe Product IDENTIFICATION SYSTEM USING QRCODE
}

\author{
Udhaya Nila $^{1}$ and Abalin Luther ${ }^{2}$ Aathi Vignesh ${ }^{3}$ \\ ${ }^{1}$ Department of Computer Application, Francis Xavier Engineering College \\ ${ }^{2}$ AP,Department of Computer Application, Francis Xavier Engineering \\ College \\ ${ }^{2}$ Department of Computer Application, Francis Xavier Engineering College
}

\begin{abstract}
Every popular brand has fake manufacturers selling a counterfeited item at cheaper rates. Mostly counterfeiting medicine are selling to customer. For these factors combined with block chain technology can lead to an efficient comprehensive approach to reduce counterfeiting. Pharmaceutical organizations face many challenges regarding counterfeit medicines. Detecting fault medicines so that it will save public life. To discover the consciousness of the fake medication issue which requires an expanding security level for the appropriation of lawful pharmaceutical items. Manufacturing to user can be recorded, and the user is assured that the scans weren't faked. The fake products can be identified by using $Q R$ code and it handles the product data
\end{abstract}

KEYWORDS

component, formatting, style, styling, insert (key words)

\section{INTRODUCTION}

This Medicine counterfeiting is a serious worldwide issue, involving networks of manufacture and distribution that are an integral part of industrialized organized crime. Using a block chain technology this medicine information will be secured. If at any stage counterfeit medicine is introduced into the system, it will be detected immediately, and its further penetration will be stopped. This paper aims to address the issue of drug safety using block chain and encrypted QR (quick response) code security. Results show that the system thus formed is computationally intensive but offers a reliable solution to the menace of fake medicines

\section{Problem Statement}

The growth in medical industry is immense but also it has been developed in production of counterfeit drugs. The market cost of pharmaceutical counterfeiting has reached billions of dollars annually. In most existing the fake medicines have been found using Bar codes by alphanumeric. Bar codes can be scanned in a line. In order to have a good medical industry, need to prevent from fake drugs. The objective of the system is to identify the counterfeit drugs. This can be accomplished by adding up data about the medicine into its QR code 


\section{- Architectural Diagram}

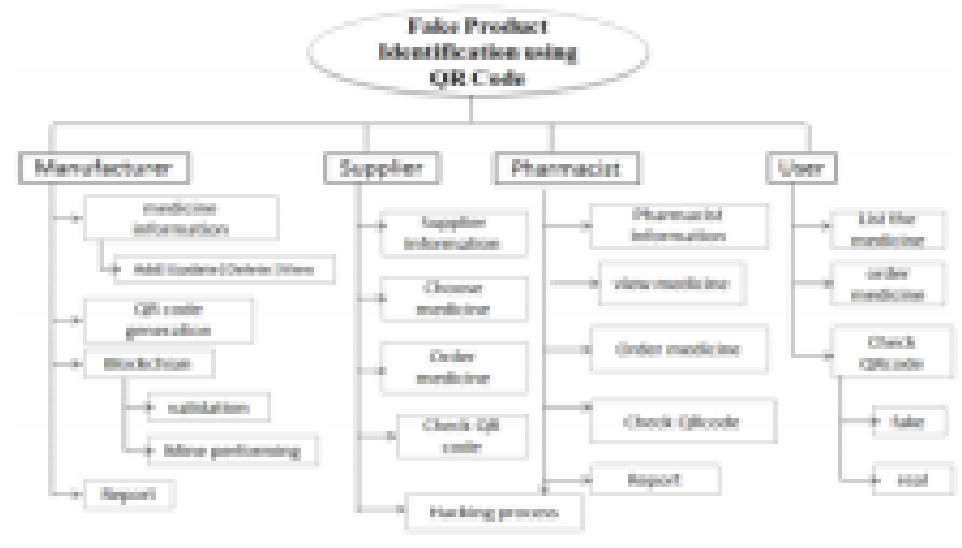

Figure-1 Architecture Diagram

\section{EXPERIMENTS AND RESULTS}

\section{Module}

\section{A. Manufacturer}

Manufacturer will register and login to the system by using valid credentials. Then manufacturer can add the products in its database. They also generate the QR code in the products.

\section{B. Supplier}

Supplier will register and login to the system by using valid username and password. Supplier will view the product list and if want they can place the order of that drugs by scanning the QR code

\section{Pharmacist}

Pharmacist will also register and login to the system with valid credentials. Pharmacist view the patients request and also view the available products list and if want then they can place the order of that drugs by scanning the $\mathrm{QR}$ code

\section{User}

User will register and login to the system using valid username and password. User place its order buy the drugs and at last logout from the system. 


\section{OUTPUT SCREEN}

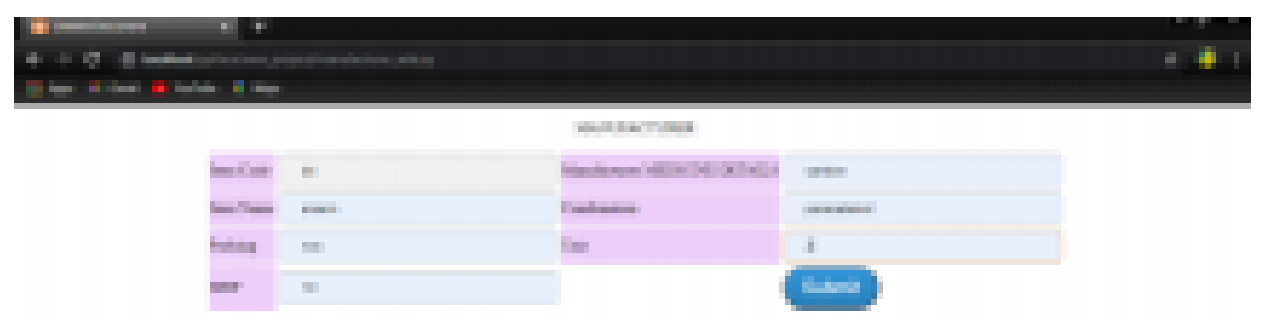

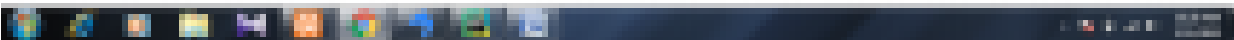

Figure- 2 Create Medicine

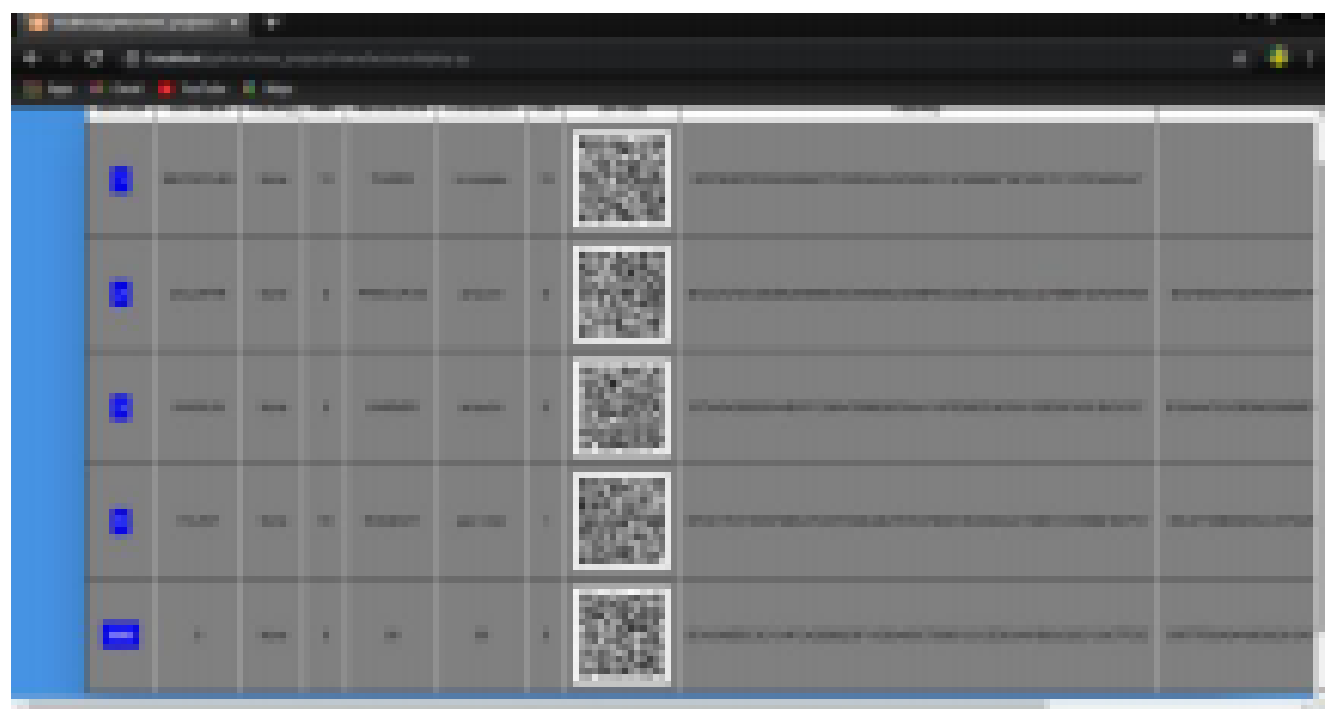

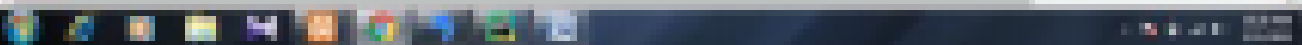

Figure-3 Manage Medicine 


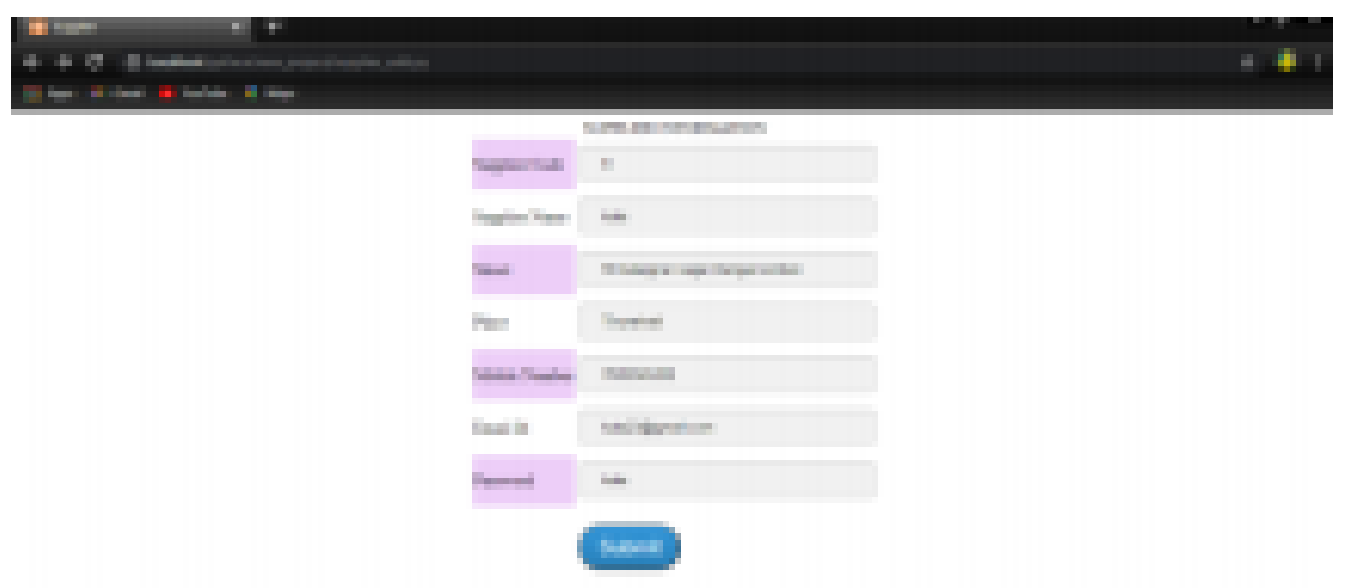

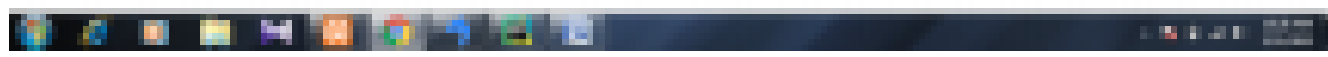

Figure-4 Adding Supplier

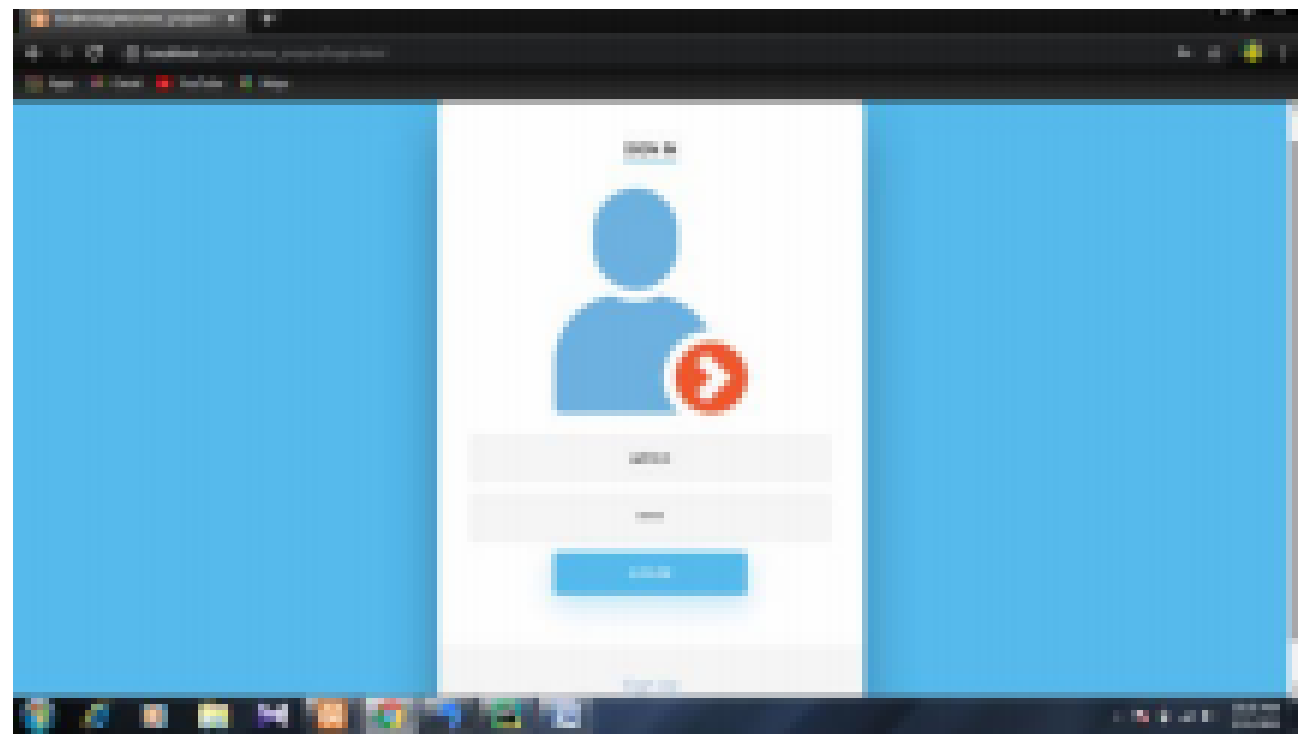

Figure-5 Admin Login 


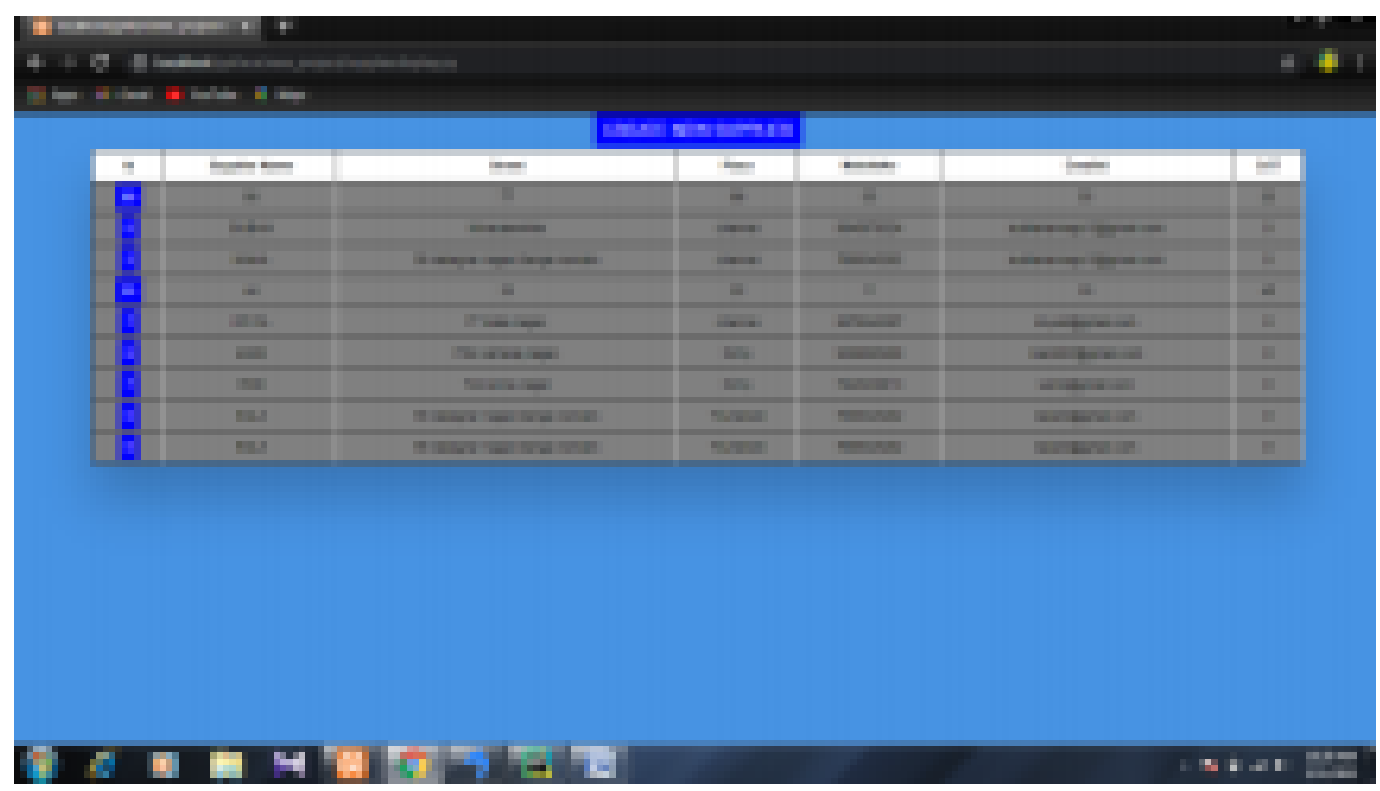

Figure-6 Manage Supplier

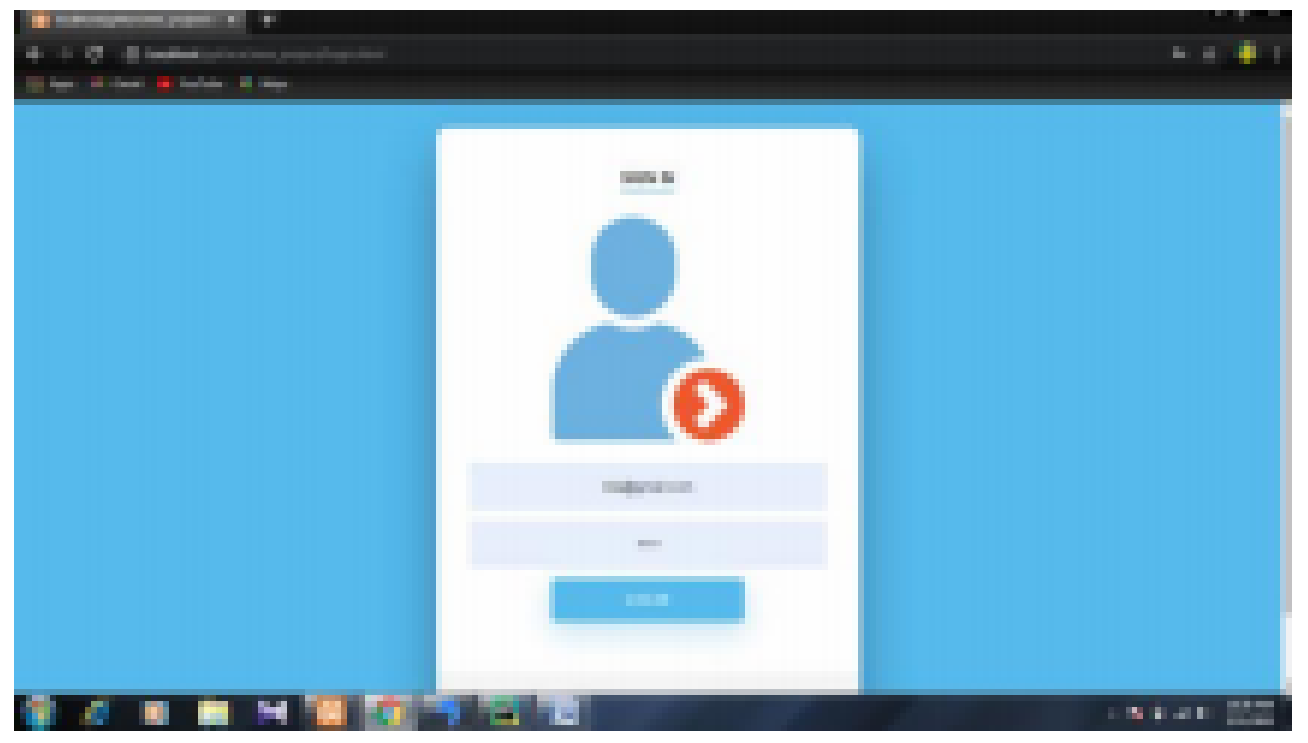

Figure-7 User Login 


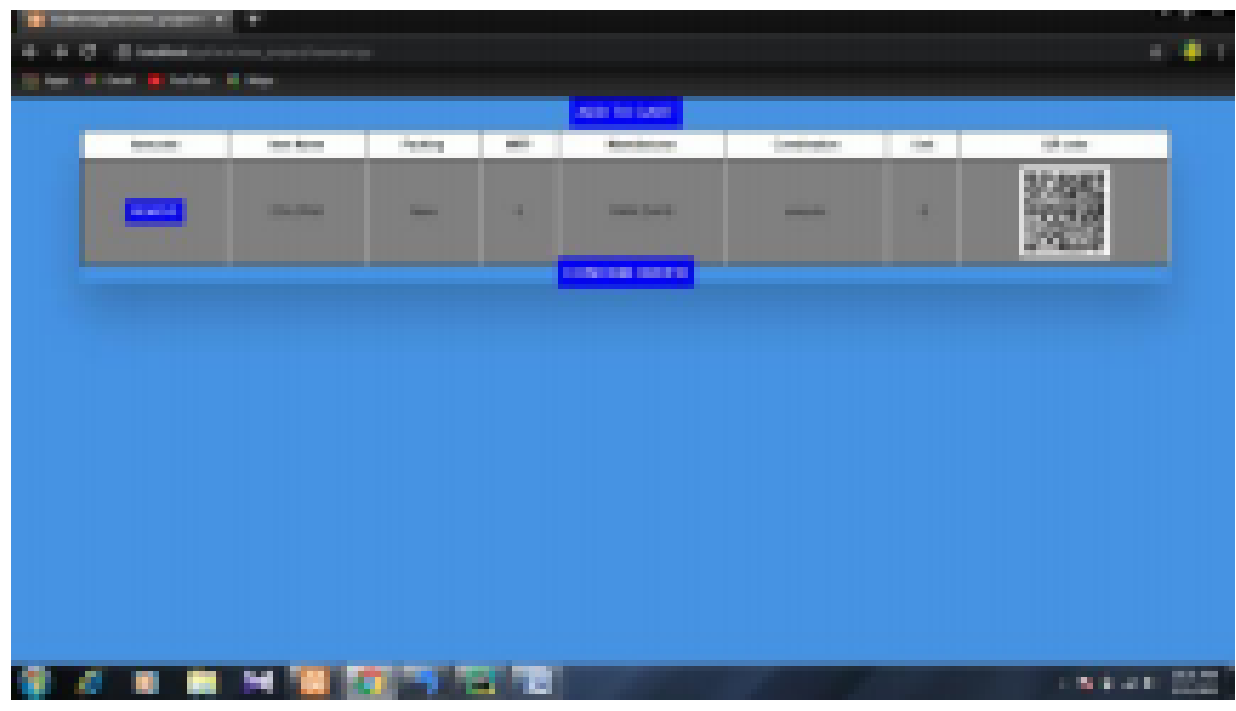

Figure-8 Order

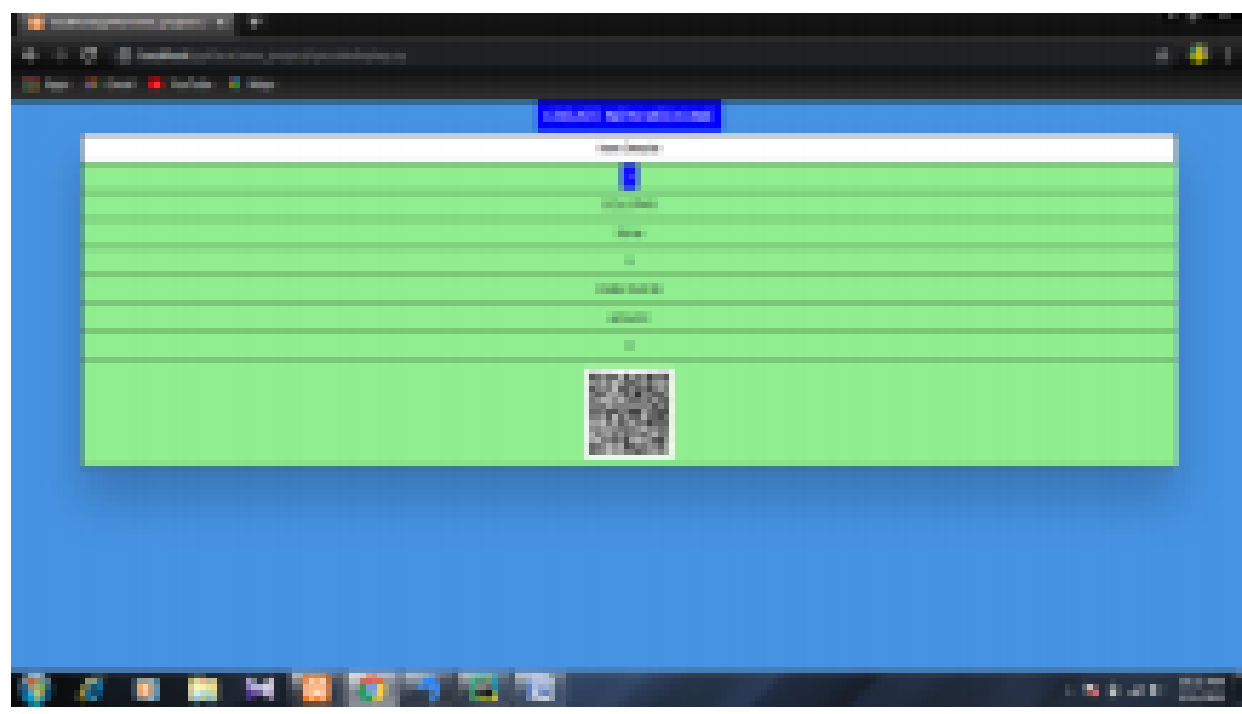

Figure-9 Check QRcode

\section{Performance Analysis}

The existing and proposed system are analysed. . The problem identified existing is system is the growth in medical industry is immense but also it has been developed in production of counterfeit drugs and proposed system gadget may be used in pharmaceutical industry to track the tablets from its manufacturing until its delivery to patient.Nearly $70 \%$ performance has been increased.

\section{CONCLUSION}

The Fake product identification system is developed using python and My SQL. This web application provides awareness of counterfeit drugs to the user. QRcode are used to identify the fake product. Manufacturer will generate a QRcode for each product. Then through the web site the user can buy the medicine using QRcode. If the medicine is fake it will generate a fake identification. 


\section{FUTURE ENHANCEMENT}

In future we implement this in android application. Manufacturer can identify the location while the customer who check the QRcode that the result is fake. If the user result.

\section{REFERENCE}

[1]Jen-Hung Tseng, Yen-Chih Liao, Bin Chong and Shih-wei Liao, "Governance on the Drug Supply Chain via Gcoin Blockchain", International Journal of Environment Research and Public Health, MDPI, 2018.

[2]Andrew O'Hagan, April Garlington, "Counterfeit drugs and the online pharmaceutical trade, a threat to public safety", Forensic Research Criminology International Journal, Volume 6 Issue 3 - 2018.

[3]Xiaoguang Liu, Ziqing Wang, ChunhuaJin, Fagen Li, And Gaoping Li, "A Block chain-based Medical Data Sharing and Protection Scheme", IEEE Access ( Volume: 7 ), 2019.

[4] A. K. Jha, D. Doolan, D. Grandt, T. Scott, and D. W. Bates, "The use of health information technology in seven nations," Int. J. Med. Inform., vol. 77, no. 12, pp. 848-854, 2008

[5] X. Qi, B. S. Emmanuel, O. Kwame, G. Jianbin, D. Xiaojiang And G.Mohsen, "MeDShare: TrustLess Medical Data Sharing Among Cloud Service Providers via Blockchain," IEEE Access, 2017.

[6] G. S. Birkhead, M. Klompas, and N. R. Shah, "Uses of electronic health records for public health surveillance to advance public health," Annu. Rev. Public Health, vol. 36, pp. 345-359, Mar. 2015

[7] P. T. S. Liu, "Medical record system using blockchain, big data and tokenization,"in Proc. 18th Int. Conf. Inf. Commun. Secur. (ICICS), vol. 9977.

Singapore, Nov./Dec. 2016, pp. 254261.

[[8] X. Yue, H. Wang, D. Jin, M. Li, andW. Jiang, "Healthcare data gateways: Found healthcare intelligence on blockchain with novel privacy risk control," J. Med. Syst., vol. 40, p. 218, Oct. 2016.

[9] W. Raghupathi and V. Raghupathi, “Big data analytics in healthcare: Promise and potential," Health Inf. Sci. Syst., vol. 2, no. 1, p. 3, 2014.

[10] Wilson JM, Kinghorn R. The Global Risk of Product Counterfeiting: Facilitators of the Criminal Opportunity. Michigan State University Centre for Anti-Counterfeiting and Product Protection; 2015. 


\section{AUTHORS}

Ms. T. Udhaya Nila doing final year MCA in Francis Xavier Engineering College

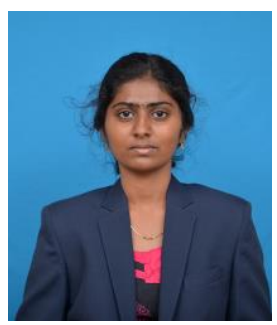

Mrs. J. Abalin Luther is working as Assistant Professor in the Department of Computer Applications, Francis Xavier Engineering College. She is having teaching experience of 5+ years. Her area of interest is Wireless Sensor networks

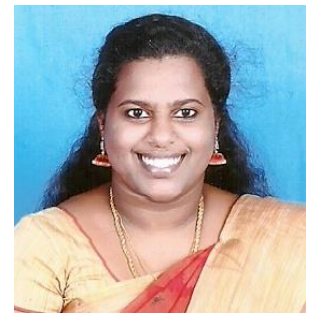

Mr. K. Aathi Vignesh doing first year MCA in Francis Xavier Engineering College

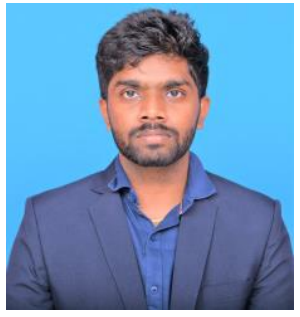

